\title{
THE PHYSICAL ACTIVITY LEVEL AND REACTION TIME DURING COVID 19 PANDEMIC
}

\author{
Liliana-Elisabeta Radu, Ileana-Monica Popovici, Renato-Gabriel \\ Petrea, Alexandru-Rares Puni \\ University Alexandru Ioan Cuza of Iasi, Romania
}

\begin{abstract}
The outbreak of the COVID-19 pandemic has a huge global impact in terms of public health, economic activities, employment, psychological and social life. The educational system had to adapt to the conditions imposed by avoiding the spread of coronavirus among pupils and students. The purpose of this study is to find out if the level of physical activity influence the reaction time using dominant and non-dominant hand. We collected data from 83 students (age ranged between $15-24$ years; $M=49, f=34$ ) who participated to the study voluntarily. To measure physical activity index we have used three items about type of physical activity performed, frequency and duration. In addition, to measure reaction time we have used Reaction Time Test and Aim Trainer Test. Each student completed and assessed himself the questionnaire and the tests online. Data were recorded and analysed in SPSS (version 20.0). The level of physical activity relieved that $18,1 \%$ of subjects are very active, $26,5 \%$ are active, $20,5 \%$ have an acceptable level of physical activity, $12 \%$ are insufficient active, and $22,9 \%$ are sedentary. The values of reaction time for both tests are fastest for subjects with insufficient level of physical activity for dominant hand. The sedentary person are fasted reaction time with non-dominant hand in Reaction Time Test, and the very active subjects are fasted reaction time in Aim Trainer Test. The results has limitations, conducted by speed of Internet connection, and type of devise used in performing tests.
\end{abstract}

Keywords: COVID, health, physical activity, reaction time, student, tests.

\section{Introduction}

Physical activity includes all forms of active recreation, participation in sports activities, as well as activities carried out within the school curriculum and around the house and garden (Nae, 2016). Regular physical activity is beneficial for both the body and the mind. Generally, physical activity may reduce high blood pressure, help maintain optimal weight balance, lower the risk of heart disease, stroke, type 2 diabetes, and various types of cancer (Lavie et al., 2019 Jiménes-Pavón et al., 2020). In addition, 
physical activity improves muscle power and increases balance, flexibility, and well-being (Cooper et al., 2020; Foster, Armstrong, 2018). Among children, regular physical activity helps support healthy growth and development and reduce the risk of disease onset; through regular exercising, children may develop fundamental movement skills and they may build social relations (Landry, Discoll, 2012).

The COVID-19 pandemic has influenced the physical activity of most population and it has decreased the opportunities of practicing regular physical exercises in fitness centres and gyms, parks, stadiums, or other locations (Kaur et al., 2020). Local public health authorities have provided regulations concerning the restrictions on the number of persons able to attend, use the equipment, as well as safety and hygiene measures to respect by the persons who wish to carry out a type of outdoors physical activity. Furthermore, physical health services providers have adapted to the current situation and they have offered online classes, in order to assist the persons who chose to carry out physical activities at home, individually. In this situation, the physical activity of pre-university and university students was affected, given that schools and universities had to teach online classes. Before the emergence of this pandemic, studies have highlighted that young people included the use of Internet as an important aspect of their lives; they reported using the Internet several times a week (Laposis, Petsiou, 2017; Tremblay et al., 2014). After the spread of the virus, schools closed their gates and had to provide online teaching, to help stop the pandemic from evolving. This transition to online teaching had an impact not only on teachers, (who had to modify their lessons) but on University students, too, who had to adapt to a new learning setting.

The purpose of our study is to determine whether there are any associations between the level of physical activity and the visual reaction time during the COVID-19 pandemic.

\section{Methodology}

The present study includes a sample of 83 students aged 18-25 years old, school students and university students. The study was conducted in the period January-February 2021 before the exam session of the university students and the inter-semester holiday of pre-university students. We mention that in this period, the subjects carried out their educational activities online. Potention respondents were electronically invited to participate through social media platform and email list servs of students. Students were directed to an online form directly from email or social media post. The form contained explanation regarding physical activity questionnaire, as well as links to accessing the tests regarding the reaction time. The tests 
were self-administrated. In order to assess the level of physical activity, the questionnaire regarding the Physical activity index adapted after Dumitru (1997) was applied; it comprises three items: effort intensity by the type of physical activity, frequency of activities, and effort duration, each with four or five choices. The evaluation was conducted based on the score obtained for each item, by applying the following formula: intensity $\times$ duration $\times$ frequency.

In order to determine the reaction time, we used the Reaction Time Test (RTT) and the Aim Trainer Test (AT), for both the dominant hand (DH) and the non-dominant hand (NDH), developed online to measure abilities with brain games and cognitive.

Reaction Time Test consists in clicking as fast as possible on a screen as the colours change, with different messages for each: red colour - waiting green, green colour - click, blue colour - click to keep going. We recorded the reaction time as the green colour emerged, which occurred five times during the test. After the last click, the screen displays the average obtained. Subjects were asked to perform the test using both the dominant and the non-dominant hand, as well as to fill the forms with averaged calculated automatically by the web page

Aim Trainer Test consists in touching 30 targets featured on the screen as fast as possible. At the end of the test, time in milliseconds is displayed.

The above-presented research tools were introduced in a Google form, with reference to the webpage for the tests in an online format. The form was transmitted using the internal communication platforms (webex, meet, mail) along with filling instructions for self-administration. Participation was anonymous and voluntary, using their own device (namely, desktop, laptop with a mouse, laptop with touchpad, telephone).

The data filled out in the form were collected automatically in an Excel document. In order to analyse the data, SPSS version 20.0 was used. Descriptive analysis, Independent Samples test for equality of mean, and One Way Anova Multiple Comparison were used for the statistical analysis. The level of statistical significance was set at $p<.005$.

\section{Results}

Based on the statistical analysis of results concerning the physical activity index (IAF), the point average shows that the subjects scored an acceptable level (54.50 points). Whereas differences were found between the points obtained by gender, age, or status, the mean results range within the limits of the interval specific to the reasonable level of physical activity. Table 1 details the results concerning the physical activity level of the subjects. Hence, $18.1 \%$ have a very active lifestyle; $26.5 \%$ have an active 
lifestyle, being characterised as active and healthy; $20.5 \%$ have an acceptable lifestyle in terms of physical activity; while $12.0 \%$ and $22.9 \%$ respectively, have sedentary and almost sedentary lifestyle.

Table 1. Physical activity level

\begin{tabular}{|l|l|c|c|}
\hline \multicolumn{2}{|l|}{ Physical Activity Index } & \multicolumn{2}{c|}{ Descriptive statistics } \\
\hline Score & Evaluation & N & $\%$ \\
\hline $81-100$ & Very active & 15 & 18.1 \\
\hline $61-80$ & Active and healthy & 22 & 26.5 \\
\hline $41-60$ & Reasonable & 17 & 20,5 \\
\hline $21-40$ & Relatively sedentary & 10 & 12.0 \\
\hline$\leq 20$ & Sedentary & 19 & 22.9 \\
\hline
\end{tabular}

Table 2 shows the descriptive statistics for RTT and ATT performed by dominant and non-dominant hand in relation with age.

Table 2. Descriptive statistics of reaction time by age

\begin{tabular}{|l|l|c|c|c|c|}
\hline \multirow{2}{*}{ Age } & \multirow{2}{*}{$\mathbf{N}$} & \multicolumn{2}{|c|}{ RTT (ms) } & \multicolumn{2}{c|}{ ATT (ms) } \\
\cline { 3 - 6 } & & DH & NDH & DH & NDH \\
\hline $15-18$ & 42 & $267.10 \pm 90.75$ & $308.18 \pm 141.07$ & $638.90 \pm 198.51$ & $827.83 \pm 226.49$ \\
\hline $19-24$ & 41 & $293.00 \pm 79.26$ & $295.70 \pm 92.09$ & $651.65 \pm 197.65$ & $793.73 \pm 224.35$ \\
\hline
\end{tabular}

Independent Sample t-test for equality of means revealed non-significant differences in RTT among age groups $(p>.005$ for $\mathrm{DH}$ and $\mathrm{NDH}$ ). Also, non-significant differences were obtained for ATT $(p>$.005).

Based on descriptive statistics (Table 3), there were found statistical differences in RTT and ATT for both dominant and non-dominant hands among gender $(p<.005)$.

Table 3. Descriptive statistics of reaction time by gender

\begin{tabular}{|l|l|c|c|c|c|}
\hline \multirow{2}{*}{ Gender } & \multirow{2}{*}{ N } & \multicolumn{2}{|c|}{ RTT (ms) } & \multicolumn{2}{c|}{ ATT (ms) } \\
\cline { 3 - 6 } & & DH & NDH & DH & NDH \\
\hline Male & 49 & $262.45 \pm 68.65$ & $271.37 \pm 74.30$ & $603.35 \pm 195.97$ & $759.12 \pm 179.07$ \\
\hline Female & 34 & $310.26 \pm 98.43$ & $348.12 \pm 154.04$ & $716.44 \pm 209.67$ & $897.65 \pm 224.88$ \\
\hline
\end{tabular}

Table 4 shows that the relatively sedentary subjects recorded the best results in both tests with the dominant hand (DH), namely an average of $232.62 \mathrm{~ms}$ and $634.00 \mathrm{~ms}$, respectively, while the sedentary subjects were 
the fastest in RTT with the non-dominant hand (NDH). The most active subjects recorded the best time in ATT with NDH (761.07 ms).

Table 4. Reaction time average by physical activity level

\begin{tabular}{|l|c|c|c|c|c|}
\hline \multirow{2}{*}{ Physical Activity Index } & \multirow{2}{*}{$\mathbf{N}$} & \multicolumn{2}{|c|}{ RTT (ms) } & \multicolumn{2}{c|}{ ATT (ms) } \\
\cline { 3 - 6 } & & DH & NDH & DH & NDH \\
\hline Very active & 29 & 304.58 & 336.69 & 634.62 & 761.07 \\
\hline Active and healthy & 17 & 293.65 & 290.71 & 712.12 & 836.18 \\
\hline Reasonable & 9 & 286.44 & 293.78 & 677.78 & 767.00 \\
\hline Relatively sedentary & 13 & 232.62 & 280.62 & 634.00 & 812.08 \\
\hline Sedentary & 15 & 265.87 & 275.67 & 634.73 & 931.40 \\
\hline Total & 83 & 282.04 & 302.81 & 649.67 & 815.87 \\
\hline
\end{tabular}

Upon applying the multiple comparison with Post Hoc Tests, we obtained statistically significant differences of the reaction time with DH between the sedentary and the active subjects, between the insufficiently active and the active subjects, and between the very active subjects and those with an acceptable index of physical activity. The mean of users of the Human Benchmark website is $284 \mathrm{~ms}$, a higher value than that recorded by our subjects who used various devices (mobile phone, desktop, laptop with a mouse and without a mouse) with different processors. The author of the tests applied remind that the mobile devices tend to be slightly slower on touch compared to clicks. Furthermore, the measurement of the reaction time is affected by the lag of computers and monitors. Thus, Table 5 features the reaction time average of subjects by the device used.

Table 5. Reaction time average by technology

\begin{tabular}{|l|c|c|c|c|c|}
\hline \multirow{2}{*}{ Devices } & \multirow{2}{*}{ N } & \multicolumn{2}{|c|}{ RTT (ms) } & \multicolumn{2}{c|}{ ATT (ms) } \\
\cline { 3 - 6 } & & DH & NDH & DH & NDH \\
\hline Cellphone & 14 & 315.00 & 386.36 & 624.07 & 719.87 \\
\hline Desktop/laptop & 52 & 247.75 & 267.97 & 593.65 & 793.27 \\
\hline Laptop-touchpad & 17 & 349.12 & 351.53 & 816.71 & 989.71 \\
\hline Total & 83 & 279.86 & 304.99 & 644.47 & 821.07 \\
\hline
\end{tabular}

The calculated average highlights that users who accessed the tests from a desktop or a laptop with a mouse obtained the best reaction times in RTT $(\mathrm{DH}=247.75 \mathrm{~ms}, \mathrm{NDH}=267.97 \mathrm{~ms}$, and in ATT with $\mathrm{DH}=593.65 \mathrm{~ms}$ ), except for ATT with the non-dominant hand; the phone users obtained the 
best average score $(719.87 \mathrm{~ms})$. Other studies have found that the variety of devices may influence the measured reaction time, thus leading to differences of 10-100 ms for one answer (Plant, Turner, 2009).

\section{Discussion}

Similar findings regarding physical activity at students' level were obtained by other authors, too (Schmidt, Pawlowski, 2021; Bădău, Bădău, 2020; Leuciuc et al., 2020; Lese, 2014; Făgăraș et al., 2015; Radu et al., 2015) both before and during the COVID-19 pandemic. Online learning has become a necessary strategy for teaching in the pandemic (Chen et al., 2020), but we must take in consideration that most people changed their lifestyles by transforming classical active activities into physically passive online activities (Bădău. Bădău, 2020; Jukic et al., 2020).

Recent studies in this context of pandemic shows that students become more autonomous in reading, and in understanding guidance in online learning (Popa et al. 2020), male students are technologically better equipped than female students (Batez, 2021), and also are mostly physical active comparative with female students, and has better reaction time also (Leuciuc et al., 2020).

During the pandemic reported that daily sitting time increased from $5 \mathrm{~h}$ to $8 \mathrm{~h}$ per day (Zheng et al., 2020). This may be explained by staying home, online teaching, online and multiplayer games, social media socialisation (Lesser, Nienhuis, 2020; Zheng et al., 2020). One of the benefits of the increase of screen time during pandemics include cognitive skills development (Barr, 2017; Barr, Copeland-Stewart, 2021). On the other hand, reaction time can be improved by 0.125 after regular training (Șenol et al., 2020). The evidence of other researcher show us that athletes or active students had better results in reaction time comparative with those who did not do sports (Temur, Bayton, 2019; Șenol, et al., 2020). Future investigations may add supplementary evidences in sedentary students reaction time based on good reflexes as a result of the increase of screen time.

Conclusive evidence shows that the results obtained in web-based tests are generally comparable to those generated by traditional way (Germine et al., 2012; Hilbig, 2016). In different areas as sports, academic, and other tasks of daily life, reaction time is a relevant variable (Metin et al., 2016). Previous research relieved that those who did more hours of physical activity showed less reaction time (Reigal et al., 2019) and groups divided according with type of sports performed support the idea that sports practice could be a useful activity to develop reaction time (Cojocariu et al., 2019; van de Water et al. 2017; Kirk, Grey, 2017). 


\section{Conclusions}

The study conducted during the COVID-19 pandemic provides important information regarding physical activity and the reaction time obtained after the online assessment, using their own devices for accessing and solving the tests. Hence, the students with a high index of physical activity (active lifestyle) obtained the lowest values of the reaction time in both hands, except for the non-dominant hand for the test involving the 30 targets to aim. On the other hand, we obtained a positive consequence of the sedentary students on the reaction time, because they obtained the best scores, which reflected the unfolding of other activities involving activities with the hands.

Whereas the study may have several limitations, findings indicate subjects' behaviours in this particular situation, entailing a lower level of physical activities and an educational process involving more screen time. Thus, in the self-assessment of physical activity index, subjects tend to overestimate their potential, reason for which we recommend the use of devices recording physical activity. Secondly, the data were collected online through self-assessment and we entrusted the subjects with the appraisal. Not least, participants used their own technology to accomplish the tasks required by the tests proposed, which were influenced by Internet speed, by the processor and the variety of devices. In the future, we recommend similar conditions for accessing online tests.

\section{References}

Barr, M. (2017). Video games can develop graduate skills in higher education students: A randomized trial. Computers \& Education, 1(3), 86-97. https://doi.org/10.1016/j. compedu.2017.05.016

Barr, M. \& Copeland-Stewart, A. (2021). Playing Video Games during the COVID-19 Pandemic and Effects on Players' Well Being. Games and Culture, $O(0), 1-18$. https://doi. org $/ 10.1177 / 15554120211017036$

Batez, M. (2021). ICT Skills of University Students from the Faculty of Sport and Physical Education during the COVID-19 Pandemic. Sustainability, 13, 1711. https://doi. org/10.3390/su13041711

Bădău, A. \& Bădău, D. (2020). The difficulties perceived by students from specialization Physical education and sports in the online education process. Health, Sports \& Rehabilitation Medicine, 21(4) 217-223. https://doi.org/10.26659/pm3.2020.21.4.217

Chen, T., Peng, L., Jing, B., Wu, C., Yang, J. \& Cong, G. (2020). The impact of the COVID-19 pandemic on user experience with online education platforms in China. Sustainability 2020, 12, 7329. https://doi.org/10.3390/su12187329

Cojocariu, A., Ungurean, B., Oprean, A. \& Puni, A. (2019). The variability of visual choice reaction time to different colors in male non-athletes and qwan ki do elite athletes. Archives of Budo, 15, 303-309. http://archbudo.com/view/abstract/id/13044 
Cooper, R., Stamatakas E. \& Hamer, M. (2020). Association of sitting and physical activity with grip strenght and balance in mid-life: 1970 British Cohort Study, Scandinavian Journal of Medicine and Science in sport, 30(12), 2371-2381. https://doi.org/10.1111/sms.13793

Dumitru, G. (1997). Sanatate prin sport pe intelesul fiecaruia, (Health through sport for everyone). Ed. FRST, Bucuresti.

Făgăraș, P. S., Radu, L. E. \& Vanvu, G. I. (2015). The Level of Physical Activity of University Students, Procedia-Social and Behavioral Sciences, 197, 1454-1457. https:// doi.org/10.1016/j.sbspro.2015.07.094

Foster, C. \& Armstrong, M. (2018). What type of physical activities are effective in developing muscle and bone strenght and balance? Journal of Frailty, Sarcopedia \& Falls, 3(2), 58-65. DOI: 10.22540/JFSF-03-058

Germine, L., Nakayama, K., Duchaine, B. C., Chabris, C. F., Chatterjee, G. \& Wilmer, J. B. (2012). Is the Web as good as the lab? Comparable performance from Web and lab in cognitive/perceptual experiments. Psychonomic Bulletin \& Review, 19, 847-857. DOI:10.3758/S13423-012-0296-9

Hilbig, B. E. (2016). Reaction time effects in lab-versus Web-based research: Experimental evidence, Behavioral Research Methods, 48, 1718-1724. doi: 10.3758/s13428-015-0678-9

Jiménez-Pavón, D., Carbonell-Baeza, A. \& Lavie, C. J. (2020). Physical exercise as therapy to fight against the mental and physical consequences of COVID-19 quarantine: special focus in older people. Progress in Cardiovascular Diseases 24, 386-388. doi: 10.1016/j.pcad.2020.03.009

Jukic, I., Calleja-Gonzales, J., Cos, F., Cuzzolin, F., Olmo, J., Terrados, N., Njaradi, N., Sassi, R., Requena, B., Milanovic, I., Krakan, I., Chatzichristos, K. \& Alcarez, p. E. (2020). Strategies and solutions for team sports athletes in isolation due Covid 19. Sports, 8(4), 56. DOI: $10.3390 /$ sports 8040056

Kaur, H., Singh, T., Arya, Y. K. \& Mittal, S. (2020). Physical Fitness and Exercise during the COVID-19 Pandemic: A Qualitative Enquiry. Frontiers in Psychology, 11, 590172. https://doi.org/10.3389/fpsyg.2020.590172

Kirk H., Gray K., Ellis K., Taffe J. \& Cornish K. (2017). Impact of attention training on academic achievement, executive functioning, and behavior: a Randomized controlled trial. American Journal on Intellectual and Developmental Disabilities, 122, 97-117. https:// doi.org/10.1352/1944-7558-122.2.97

Landry, B. W. \& Driscoll, S. W. (2012). Physical Activity in Children and Adolescents, $P M \& R$ : the Journal of Injury, Function, and Rehabilitation, 4, (11), 826-832. https://doi.org/ 10.1016/j.pmrj.2012.09.585.

Lapousis, G. \& Petsiou, E. (2017). Thr Impact of The Internet Use in Physical Activity, Exercise and Academic Performance of School Students Aged 14-16 Years Old, International Journal of New Technology and Research, 3(2), 12-16. https://www.ijntr.org/ download_data/IJNTR03020044.pdf

Lavie, C. J., Ozemek, C., Carbone, S., Katzmarzyk, P. T. \& Blair, S. N. (2019). Sedentary Behavior, Exercise, and Cardiovascular Health. Circulation Research, 124, 799-815. doi: 10.1161/CIRCRESAHA.118.312669

Lese, A. C. (2014). Physical Education between the Necessary and the Compulsory in Artistic Academic Education. Procedia-Social and Behavioral Sciences, 117, 98-103. Doi: $10.1016 /$ j.sbspro.2014.02.185

Lesser, I. A. \& Nienhuis, C. P. (2020). The impact of COVID-19 on physical activity behavior and well-being of Canadians. Journal of Environmental Research and Public Health, 17, 3899. http://doi.org/10.3390/ijerph17113899 
Leuciuc, F. V., Ghervan, P., Popovici, I. M., Benedek, F., Lazar, A. G. \& Pricop, G. (2020). Social and Educational Sustainability of the Physical Education of Romanian Students and the Impact on Their Physical Activity Level, Sustainability 12, (21), 9231. https://doi.org/10.3390/su12219231

Metin, B., Wiersema, J. R., Verguts, T., Gasthuys, R., van Der Meere, J. J., Roeyers, H., et al. (2016). Event rate and reaction time performance in ADHD: testing predictions from the state regulation deficit hypothesis using an ex-Gaussian model. Child Neuropsychology, 22(1), 99-109. https://doi.org/10.1080/09297049.2014.986082

Nae, I. C. (2016). Physical Activity And Nutrition In Adult Life In Romania. Marathon, 8(2), 224-228. https://ideas.repec.org/a/rom/marath/v8y2016i2p224-228.html

Plant, R. R. \& Turner, G. (2009). Millisecond precision psychological research in a world of commodity computers: new hardware, new problems? Bahavior Research, 41(3), 598614. DOI: 10.3758/BRM.41.3.598. PMID: 19587169.

Popa, D., Repanovici, A., Lupu, D., Norel, M. \& Coman, C. (2020). Using Mixed Methods to Understand Teaching and Learning in COVID 19 Times. Sustainability, 12, 8726. https://doi.org/10.3390/su12208726

Radu, L. E., Făgăraş, P. S. \& Vanvu, G. (2015). Physical Activity Index of Female University Students, Procedia-Social and Behavioral Sciences, 191, 1763-1766. DOI: 10.1016/ j.sbspro.2015.04.375

Reigal, R. E., Barrero, S., Martin, I., Morales-Sanchez, V., Juarez-Ruiz, de M., R. \& Hernandez-Mendo, A. (2019). Relationship between Reaction Time, Selective Attention, Physical Activity, and Physical Fitness in Children, Frontiers in Psychology, 10, 2278. doi: 10.3389/fpsyg.2019.02278

Schmidt, T. \& Pawlowski, C. S. (2021). Physical Activity in Crisis: The Impact of COVID-19 on Danes' Physical Activity Behavior. Frontiers in Sports and Active. Living 2, 610255. DOI: $10.3389 /$ fspor.2020.610255

Şenol, D., Altinoglu, M., Kisaoglu, A., Toy, Ș, Duz, S. \& Ozbog, D. (2020). Comparison of Visual and Auditory Reaction Times in Athletes and Sedentary Individuals with Different Somatotypes: A Neuroperformance Study. International Journal of Sport Studies for Health, 3(1), e100475. DOI: 10.5812/intjssh.100475

Temur, H. B. \& Baytar, R. (2019). Comparison of the Reaction Time Period of Individuals in Sport, Fine Arts and Classroom Education. Asian Journal of Education and Training, 5(3), 495-500. https:doi.org/10.204481/journal.522.2019.53.495.500

Tremblay, M. S., Gray, C. E., Akinroe, K., Harrington, D. M., Katzmarzyk, P. T., Lambert, E. V. et all. (2014). Physical Activity of Children: A global Matrix of Grades Comparing 15 Countries, Journal of Physical Activity and Health, Supp 1, s113-s125. https:// doi.org/10.1123/jpah.2014-0177

Van de Water, T., Huijgen, B., Faber, I. \& Elferink-Gemser, M. (2017). Assessing cognitive performance in badminton players: a reproducibility and validity study, Journal of Human Kinetices, 55, 149-159. DOI: 10.1515/hukin-2017-0014

Zheng, C., Huang, W. Y., Sheridan, S., Sit, C. H., Chen, X. K. \& Wong, S. H. (2020). COVID-19 Pandemic Brings a Sedentary Lifestyle in Young Adults: A Cross-Sectional and Longitudinal Study. International Journal of Environmental Research and Public Health, 17(17), 6035. DOI: 10.3390/ijerph17176035 